\title{
PENGARUH KEBIASAAN MINUM TEH BERKUALITAS TERHADAP GAYA HIDUP KONSUMEN DI TEA ADDICT LOUNGE, JAKARTA
}

\section{INFLUENCE OF DRINKING QUALITY TEA TOWARDS CONSUMER LIFESTYLE IN TEA ADDICT LOUNGE, JAKARTA}

\author{
Dikki Zuchradi Choesrani' ${ }^{1)}$, \\ ${ }^{1)}$ Program Studi Perhotelan, AKPAR Bunda Mulia
}

18 Mei 2020

\begin{abstract}
Along with the development of the times that have an impact on human behavior and human life that is more sociable, Lounge becomes part of lifestyle and human needs in daily life in relieving fatigue after carrying out daily routine activities. With the social lifestyle section, gathering in one place with friends, friends outside the environment of daily activities is a routine at the end of the day, just to exchange ideas and share experiences. This makes business people also begin to look at businesses in the field of tea serving by establishing various tea house or café businesses that offer various types of tea from various parts of the world. One of them is Tea Addict Lounge, offering various types of tea from Indonesia.

The purpose of this study was to determine the relationship between tea drinking habits with consumer lifestyles in the Tea Addict Lounge. Where in this study discusses more deeply whether consumers who come to the Tea Addict Lounge based on the knowledge they have about tea or just a lifestyle. Data were collected through a questionnaire using a Likert scale of 1-5 and consumer interviews in the Tea Addict Lounge as many as 62 respondents within a period of 3 months. This study uses Pearson correlation to calculate the results of the relationship between the two variables.

The results of this study indicate that the relationship between the two variables is 0.123 . Where these figures indicate that there is a very weak relationship between tea drinking habits and consumer lifestyles in Tea Addict. Meanwhile, tea drinking habits affect consumers' lifestyles by $1.5 \%$, the remaining $98.5 \%$ is influenced by other things not tested in this paper.
\end{abstract}

Keywords: Quality tea; Lifestyle, Tea Lounge

\section{ABSTRAK}

Seiring dengan perkembangan zaman yang berdampak pada perilaku manusia dan kehidupan manusia yang lebih bersosialisasi, Lounge menjadi bagian gaya hidup dan kebutuhan manusia dalam kehidupan sehari hari dalam melepas rasa penat setelah menjalankan kegiatan rutinitas harian. Dengan adanya bagian gaya hidup bersosialisasi, maka berkumpul di satu tempat bersama kawan - kawan, sahabat di luar lingkungan kegiatan harian sudah merupakan rutinitas di akhir hari, hanya untuk sekedar bertukar pikiran dan berbagi pengalaman. Hal ini membuat para pebisnis juga mulai melirik usaha di bidang penyajian teh dengan mendirikan berbagai bisnis tea house atau café yang menawarkan beragam jenis teh dari berbagai penjuru dunia. Salah satunya Tea Addict Lounge, menawarkan berbagai jenis teh dari Indonesia.

Tujuan dari penelitian ini adalah untuk mengetahui hubungan antara kebiasaan minum teh dengan gaya hidup konsumen di Tea Addict Lounge. Dimana dalam penelitian ini membahas lebih dalam apakah konsumen yang datang ke Tea Addict Lounge berdasarkan pengetahuan yang mereka miliki tentang teh atau hanya sekedar gaya hidup saja. Data dikumpulkan melalui kuesioner yang menggunakan skala likert 1-5 dan wawancara konsumen di Tea Addict Lounge sebanyak 62 responden dalam kurun waktu 3 bulan. Penelitian ini menggunakan korelasi pearson untuk menghitung hasil dari hubungan kedua variable.

Hasil dari penelitian ini menunjukkan bahwa hubungan antara kedua variabel tersebut sebesar 0,123. Dimana angka tersebut menunjukkan bahwa terdapat hubungan yang sangat lemah antara kebiasaan minum teh dan gaya hidup konsumen di Tea Addict. Sementara itu, kebiasaan minum teh mempengaruhi gaya hidup konsumen sebesar 1,5\%, sisanya sebesar 98,5\% dipengaruhi oleh hal - hal lain yang tidak diuji dalam karya tulis ini.

Keywords : Teh berkualitas; Gaya Hidup, Tea Lounge 


\section{PENDAHULUAN}

Minuman teh biasa dinikmati oleh masyarakat Indonesia setiap hari. Tanpa kita sadari, teh telah menjadi salah satu bagian kebiasaan hidup bagi semua orang. Tanpa membedakan kalangan dari gender untuk menggemari minuman teh dengan tujuan konsumsi yang berbeda - beda, antara lain untuk kesehatan dan di percaya oleh sebagian masyarakat untuk menurunkan berat badan, menambah kesegaran, atau sekedar untuk menghangatkan suasana saat berkumpul bersama keluarga dan teman. Contohnya di berbagai kota besar terdapat banyak tempat / angkringan yang menjadi salah satu tempat terfavorit masyarakat dari berbagai kalangan dan status sosial, seperti pebisnis, pelajar pedagang kaki lima tak segan berkumpul dan mengobrol sambil menikmati minuman teh.

Namun pada dewasa ini, kebiasaan minum teh bukan hanya sekedar tuntutan selera, tapi bagi masyarakat, ini sudah menjadi salah satu bagian dari gaya hidup / life style. Melihat kebiasaan minum teh yang telah berkembang dari tradisi budaya menjadi gaya hidup ini, para pebisnis juga mulai melirik usaha di bidang penyajian teh dengan mendirikan berbagai bisnis tea house atau café yang menawarkan beragam jenis teh dari berbagai penjuru dunia. Pada 2018 Kementrian Perindustrian (Kemenperin) menyebut sektor makanan dan minuman berhasil menyumbang produk domestik bruto (PDB) nasional sebesar 6.34\%.

Tea Addict Lounge adalah sebuah perusahaan yang bergerak di industri makanan dan minuman dan lebih focus kepada produk minuman teh. Dengan nama Tea Addict Lounge,yang menggunakan nama Bahasa Inggris yang mempunyai arti, "Tea" berasal dari bahasa inggris dikenal sebagai jenis produk alam dari perkebunan yang hasilnya di sebut dan dikenal sebagai "daun teh", dan bilamana daun teh tersebut sudah melalui proses akan menghasilkan sebuah minuman yang mempunyai aroma dan rasa yang unik. Kata "Addict" adalah kata sifat yang mempunyai arti "kecanduan" yang disebabkan rasa suka berlebihan terhadap sebuah produk. "Lounge" adalah sebuah tempat yang dijadikan tempat berkumpul bersama teman atau keluaraga sambil menikmati hidangan yang disediakan. Jadi "Tea Addict Lounge" adalah sebuah tempat yang nyaman dimana tempat berkumpulnya orang-orang yang yang dapat menikmati dan kecanduan minuman teh.

\section{TUJUAN PENELITIAN}

Tujuan dari penelitian ini adalah untuk mengetahui apakah Tea Addict produk yang merupakan teh produk Indonesia dapat bersaing berpengaruh secara signifikan terhadap konsumennya secara kualitas atau gaya hidup.

\section{LANDASAN TEORI}

\section{A. Pengertian Teh}

Tanaman Teh disebut juga Camellia Sinensis, berasal dari tanaman yang tumbuh di daerah subtropika dengan lingkungan sejuk dengan suhu harian antara $13^{\circ} \mathrm{C}-25^{\circ} \mathrm{C}$. Cahaya matahari cerah dan kelembaban relative pada siang hari lebih dari $70 \%$. Teh dikenal sebagai spesies tunggal dengan beberapa varietas khusus, yaitu sinensis, assamica, dan irrawadiensis.

\section{B. Manfaat Teh}

Teh memiliki manfaat bagi kesehatan karena ternyata pada teh terdapat beberapa kandungan aktif dalam teh seperti: polyphenols (10-25\%), dan komponen organik lainnya seperti vitamin $\mathrm{C}(150-250 \mathrm{mg} \%)$, vitamin $\mathrm{E}(25-70 \mathrm{mg} \%), \beta$ carotene (13-20\%), caffein (45-50 $\mathrm{mg} \%$ ), dan fluor $(0,1-4,2 \mathrm{mg} / \mathrm{L})$. Sedangkan aroma dan cita rasa yang khas pada teh dikarenakan adanya komponen kandungan volatile.

Berikut komposisi kimia yang ada di dalam daun teh dapat dilihat pada table dibawah:

Indarto (2007) menyebutkan bahwa semua jenis teh mengandung tiga zat penting yang bekerja secara sinergi untuk mempengaruhi sistem metabolisme dan saraf tubuh seperti, polyphenol,Kafein,L-Theanine (asam amino non-protein). Berikut fungsi dari masing masing zat:

\section{Polifenol}

Manfaatnya:

a. Menurunkan kadar kolesterol

b. Menurunkan tekanan dan kadar gula darah c. Membantu kerja ginjal dan mencegah terjadinya batu empedu d. Memperlancar pencernaan 
e. Melarutkan lemak dan mencegah kolesterol jahat.

\section{Kafein}

Manfaatnya:

a. Bersifat sebagai mild stimulant pada sistem saraf pusat sehingga memperlancar sirkulasi darah ke otak

b. Dengan minum teh secara teratur akan menaikkan tingkat ingatan, cognitive, performance,feeling of pleasant dan mood.

\section{Essential oil}

Manfaatnya yaitu melarutkan lemak dan memperlancar pencernaan dan peredaran darah

Syahriyanti (2009:101-105) menyebutkan bahwa teh juga memiliki berbagai manfaat terhadap kesehatan, diantaranya :

a. Mengurangi resiko kanker kulit

b. Mencegah pertumbuhan kanker, jantung, stroke, dan prostat

c. Menurunkan resiko penyakit kanker

d. Menurunkan resiko terjadinya penyakit kardiovaskular

Teh mengandung kafein yang berbeda dengan kopi dan mampu merangsang sistem saraf tubuh sehingga pengambilan oksigen ke dalam tubuh menjadi lebih lancar.

\section{METODE PENELITIAN}

Dalam penulisan proyek akhir ini, penulis berusaha untuk mendapatkan dan mengumpulkan data yang tepat dan akurat dari berbagai sumber - sumber yang dapat dipercaya. Penulis juga merasa informasi yang didapatkan dari para responden tersebut sangat bermanfaat dalam penulisan proyek akhir ini.

Penelitian ini dimaksudkan untuk mengetahui pengaruh dari kebiasaan minum teh yang sering dilakukan oleh pelanggan, serta pengaruhnya terhadap Gaya Hidup konsumen yang ada di Tea Addict, Jakarta. Metodologi penelitian ini digunakan sebagai pedoman dalam melaksanakan penelitian agar peneliti dapat memperoleh data dan hasil penelitian yang baik dan tidak menyimpang dari tujuan yang sudah ditentukan.

Metode yang digunakan penulis dalam penelitian ini adalah metode deskriptif korelasional dengan mengkorelasikan kebiasaan minum teh terhadap Gaya Hidup konsumen di Tea Addict, Jakarta. Metode penelitian deskriptif korelasional adalah untuk mendeteksi sejauh mana variasi - variasi yang ada pada suatu faktor berkaitan dengan variasi - variasi pada satu atau lebih faktor lain berdasarkan pada koefisien korelasi (Suryabrata, 2003:82).

\section{A. Variabel dan Cara Pengukurannya}

Variabel adalah segala sesuatu yang akan menjadi objek pengamatan berupa suatu konsep yang mempunyai variasi nilai. Menurut Sedangkan menurut Narbuko dan Achmadi (2007:118), variabel penelitian merupakan faktor - faktor yang berperan dalam peristiwa dan gejala yang akan diteliti. Narbuko dan Achmadi (2007:119) juga menyebutkan bahwa variabel juga dapat dibagi menurut fungsinya yaitu, variabel tergantung, variabel bebas, variabel intervening, variabel moderator, variabel kendali, dan variabel rambang.

\section{Variabel Bebas (Independent variable)} Variabel bebas merupakan variabel yang menjadi sebab timbulnya atau berubahnya variabel dependen (terikat), dalam hal ini adalah ,"Kebiasaan Minum Teh"

2. Variabel Terikat (Dependent variabel)

Variabel dependen merupakan variabel yang dipengaruhi atau yang menjadi akibat, karena adanya variabel independent (bebas), dalam hal ini adalah,"Gaya Hidup".

Dalam penelitian ini skala yang digunakan untuk mengukur kebiasaan minum teh terhadap Gaya Hidup konsumen di Tea Addict, Jakarta adalah Skala Likert. Skala Likert yaitu skala yang digunakan untuk mengukur sikap, pendapat, dan persepsi seseorang atau sekelompok orang terhadap suatu kejadian atau keadaan sosial dimana variabel yang akan diukur dijabarkan menjadi indikator variabel kemudian indikator tersebut dijadikan titik awal untuk menyusun item item pernyataan.

Hal ini diperkuat oleh Kusmayadi dan Sugiarto (2000:94) sebagai berikut :

"Skala Likert merupakan alat untuk mengukur sikap dari keadaan yang sangat positif ke jenjang yang sangat negatif, untuk menunjukkan sejauh mana tingkat persetujuan atau ketidaksetujuan terhadap pernyataan yang diajukan oleh peneliti." 
Jawaban dari setiap skala instrumen yang menggunakan Skala Likert mempunyai nilai dari sangat positif sampai sangat negatif, yang dapat dilihat dari Tabel 1.

Tabel 1 Nilai untuk Jawaban Kuesioner

\begin{tabular}{cc}
\hline Jawaban & Skor / Nilai \\
\hline Sangat Setuju & 5 \\
\hline Setuju & 4 \\
\hline Kurang Setuju & 3 \\
\hline Tidak Setuju & 2 \\
\hline Sangat Tidak Setuju & 1
\end{tabular}

Variabel - variabel yang digunakan dalam penelitian ini adalah sebagai berikut :

\section{Tabel 2 Demografi Responden}

\begin{tabular}{l}
$\begin{array}{l}\text { Ketera Indikator } \\
\text { ngan }\end{array}$ \\
\hline
\end{tabular}
ngan Pengu

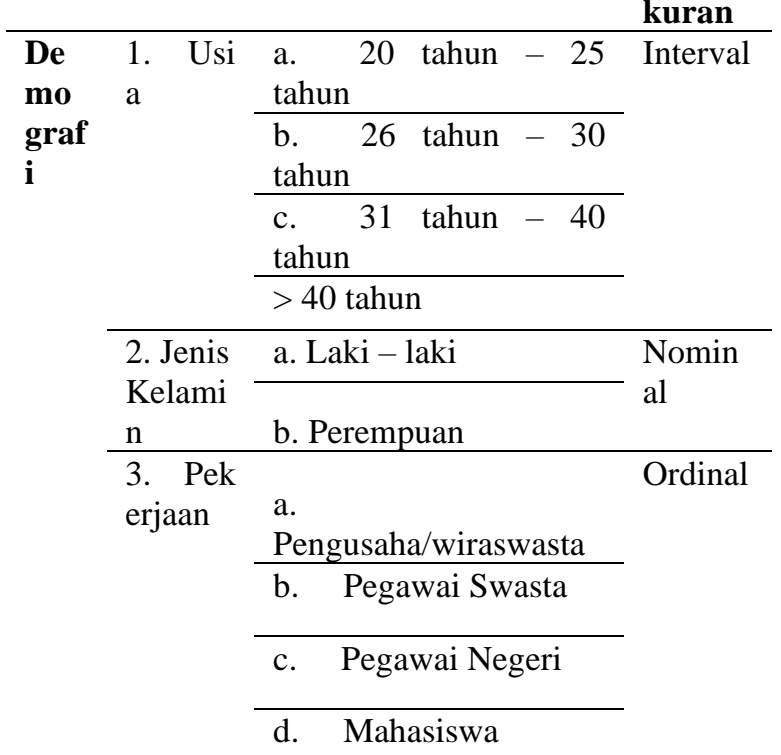

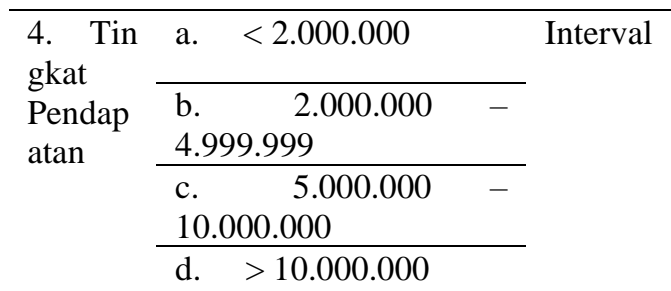

\begin{tabular}{llll}
\hline 5. Stat & a. & Menikah & Nomin \\
\cline { 2 - 3 } us & b. & Belum Menikah & al
\end{tabular}

\begin{tabular}{lll}
\hline $\begin{array}{l}\text { 6. Ref } \\
\text { erensi }\end{array}$ & $\begin{array}{l}\text { a. Keluarga } \\
\text { b. Teman }\end{array}$ & Ordinal \\
\cline { 2 - 3 } & $\begin{array}{l}\text { c. Media (TV, } \\
\text { majalah, koran) }\end{array}$ \\
\cline { 2 - 2 } & d. Dan lain - lain.
\end{tabular}

\begin{tabular}{llll}
\hline 7. Fre & a. & 1 kali & Interval \\
\cline { 2 - 3 } kuensi & b. & $2-3$ kali &
\end{tabular}

$$
\begin{array}{lll}
\text { Kedata } & \text { c. } & 4-5 \text { kali } \\
\cline { 2 - 3 } & \text { d. } & >5 \text { kali }
\end{array}
$$

\section{Tabel 3 Variabel, Sub Variabel, Indikator,

\begin{tabular}{|c|c|c|c|}
\hline No. & Variabel & $\begin{array}{c}\text { Sub } \\
\text { Variabel }\end{array}$ & Indikator \\
\hline \multirow[t]{8}{*}{1} & \multirow[t]{8}{*}{$\begin{array}{l}\text { Kebiasaan } \\
\text { Minum } \\
\text { Teh }\end{array}$} & \multirow[t]{2}{*}{ Budaya } & $\begin{array}{l}\text { Teh } \\
\text { terdapat } \\
\text { hampir di } \\
\text { seluruh } \\
\text { wilayah } \\
\text { Indonesia }\end{array}$ \\
\hline & & & $\begin{array}{l}\text { Tata cara } \\
\text { minum teh }\end{array}$ \\
\hline & & \multirow[t]{3}{*}{$\begin{array}{c}\text { Manfaat } \\
\text { Teh }\end{array}$} & $\begin{array}{l}\text { Manfaat } \\
\text { teh bagi } \\
\text { kesehatan } \\
\text { dan } \\
\text { kecantikan }\end{array}$ \\
\hline & & & $\begin{array}{l}\text { Kandungan } \\
\text { zat yang } \\
\text { terkandung } \\
\text { dalam teh }\end{array}$ \\
\hline & & & $\begin{array}{l}\text { Manfaat } \\
\text { lain dari } \\
\text { teh }\end{array}$ \\
\hline & & \multirow[t]{3}{*}{$\begin{array}{l}\text { Jenis } \\
\text { Teh }\end{array}$} & $\begin{array}{l}\text { Asal dari } \\
\text { tanaman } \\
\text { teh }\end{array}$ \\
\hline & & & $\begin{array}{l}\text { Teh dari } \\
\text { segi bentuk }\end{array}$ \\
\hline & & & $\begin{array}{l}\text { Teh dari } \\
\text { cara } \\
\text { pengolahan }\end{array}$ \\
\hline
\end{tabular} dan Skala Pengukuran}

\begin{tabular}{|c|c|c|c|c|}
\hline No. & Variabel & $\begin{array}{c}\text { Sub } \\
\text { Variabel }\end{array}$ & Indikator & $\begin{array}{l}\text { Skala } \\
\text { Pengu } \\
\text { kuran }\end{array}$ \\
\hline \multirow[t]{3}{*}{2} & $\begin{array}{l}\text { Gaya } \\
\text { Hidup }\end{array}$ & Aktivitas & $\begin{array}{l}\text { Tindakan } \\
\text { nyata yang } \\
\text { dilakukan } \\
\text { dengan } \\
\text { alasan } \\
\text { tertentu }\end{array}$ & $\begin{array}{c}\text { Skala } \\
\text { Likert } \\
\text { (Ordin } \\
\text { al) }\end{array}$ \\
\hline & & & $\begin{array}{l}\text { Tindakan } \\
\text { yang umum } \\
\text { dilakukan } \\
\text { (hal yang } \\
\text { biasa) }\end{array}$ & \\
\hline & & Minat & $\begin{array}{l}\text { Ketertarikan } \\
\text { pada } \\
\text { manfaat dan } \\
\text { jenis the }\end{array}$ & \\
\hline
\end{tabular}




\begin{tabular}{ll} 
& Tingkat \\
& keinginan \\
konsumen & untuk \\
& melakukan \\
& sesuatu \\
& terus \\
& menerus \\
\hline Opini & Jawaban \\
& lisan/tulisan \\
& dari respon \\
& spontan \\
& konsumen \\
\cline { 2 - 2 } & Deskripsi \\
konsumen \\
tentang \\
suatu objek
\end{tabular}

\section{B. Prosedur Pengumpulan Data}

\section{Data Primer}

Merupakan data yang terdapat langsung dari objek penelitian. Data primer adalah data yang dihimpun secara langsung dari sumbernya dan diolah sendiri oleh lembaga bersangkutan untuk dimanfaatkan. Untuk mengumpulkan data primer ini dengan menggunakan pengamatan, sebagai berikut :
a. Kuisioner
b. Observasi/Pengamatan
c. Wawancara

\section{Data Sekunder}

Data sekunder adalah data penelitian yang diperoleh secara tidak langsung melalui media perantara (dihasilkan pihak lain) atau digunakan oleh lembaga lainnya yang bukan merupakan pengolahnya, tetapi dapat dimanfaatkan dalam suatu penelitian tertentu (Ruslan, 2003:138).

\section{Metode Analisis Data}

Pengolahan data - data penelitian dimulai dengan mengumpulkan semua data yang ada seperti hasil observasi dan kuesioner. Lalu semua data diperiksa kelengkapannya agar cukup lengkap untuk mengolah data data tersebut. Hal yang perlu diteliti dalam mengolah kuisioner adalah kelengkapan pengisian yang berarti responden menolak memberi jawaban atau lupa mengisinya, itulah yang harus dipertanyakan kembali pada responden.

Metode yang digunakan penulis dalam menganalisis dan mengolah data-data yang telah diperoleh dalam penelitian ini adalah dengan melakukan penghitungan Korelasi Pearson.

\section{Waktu dan Tempat Penelitian}

Sesuai dengan judul yang diambil yaitu "Pengaruh Kebiasaan Minum Teh Berkualitas terhadap Gaya Hidup Konsumen di Tea Addict Lounge, Jakarta", maka penelitian ini diadakan di Tea Addict, Jakarta selama kurun waktu tiga bulan. Alamat lengkap dari Tea Addict yaitu : Jalan Wijaya 9, Kebayoran Baru, Jakarta Selatan.

\section{HASIL DAN PEMBAHASAN}

Penelitian ini menggunakan data primer dan datanya dikumpulkan dari kuesioner yang telah disebar. Responden yang menjadi objek penelitian berjumlah 62 orang. Untuk mengetahui hasil analisa dari korelasi antara kebiasaan minum teh terhadap gaya hidup konsumen di Tea Addict, maka di bawah ini penulis sajikan tabel nilai dari keseluruhan jawaban yang diperoleh dari responden dengan keterangan sebagai berikut:

\section{Karakteristik Responden}

Karakteristik responden yang diteliti dalam penelitian ini meliputi usia responden, jenis kelamin responden, pekerjaan responden, tingkat pendapatan responden, status responden, referensi responden ke Tea Addict dan frekuensi responden datang ke Tea Addict.

\section{Tabel 4}

Karakteristik Responden Berdasarkan Usia

\begin{tabular}{ccccc} 
& $\begin{array}{c}\text { Fre } \\
\text { que } \\
\text { ncy }\end{array}$ & $\begin{array}{c}\text { Perce } \\
\text { nt }\end{array}$ & $\begin{array}{c}\text { Valid } \\
\text { Percent }\end{array}$ & $\begin{array}{c}\text { Cumul } \\
\text { ative } \\
\text { Percen } \\
\text { t }\end{array}$ \\
\hline $\begin{array}{c}17 \text { tahun } \\
-25 \\
\text { tahun }\end{array}$ & 27 & 43.5 & 43.5 & 43.5 \\
\hline $\begin{array}{c}26 \text { tahun } \\
-30 \\
\text { tahun }\end{array}$ & 15 & 24.2 & 24.2 & 67.7 \\
\hline $\begin{array}{c}31 \text { tahun } \\
-40 \\
\text { tahun }\end{array}$ & 12 & 19.4 & 19.4 & 87.1 \\
\hline $\begin{array}{c}>40 \\
\text { tahun }\end{array}$ & 8 & 12.9 & 12.9 & 100 \\
\hline Total & 62 & 100 & 100 &
\end{tabular}

Klasifikasi responden berdasarkan usia dengan jumlah responden sebanyak 62 
orang, dapat diperoleh hasil bahwa 43,5\% atau sebanyak 27 konsumen yang datang ke Tea Addict berusia 17 tahun - 25 tahun. Sementara itu, konsumen yang berusia 26 tahun - 30 tahun berjumlah 15 konsumen dengan persentase sebesar 24,2\%. Konsumen Tea Addict yang berusia 31 tahun - 40 tahun sebanyak 12 konsumen dengan persentase sebesar 19,4\%. Selain itu, ada juga konsumen yang datang ke Tea Addict berusia lebih dari 40 tahun sebanyak 8 orang dengan persentase sebesar $12,9 \%$.

Tabel 5

Karakteristik Responden Berdasarkan Jenis Kelamin

\begin{tabular}{ccccc} 
& Frequency & Percent & $\begin{array}{c}\text { Valid } \\
\text { Percent }\end{array}$ & $\begin{array}{c}\text { Cumulative } \\
\text { Percent }\end{array}$ \\
\hline Pria & 29 & 46.8 & 46.8 & 46.8 \\
\hline Wanita & 33 & 53.2 & 53.2 & 100 \\
\hline Total & 62 & 100 & 100 &
\end{tabular}

Klasifikasi responden berdasarkan jenis kelamin dengan jumlah responden sebanyak 62 orang, dapat diperoleh hasil bahwa 46,8\% atau sebanyak 29 konsumen yang datang ke Tea Addict adalah laki - laki. Sementara itu, konsumen perempuan berjumlah 33 konsumen dengan persentase sebesar $53,2 \%$.

Tabel 6

Karakteristik Responden Berdasarkan Pekerjaan

\begin{tabular}{ccccc} 
& Frequency & Percent & Valid $\%$ & $\begin{array}{c}\text { Cumulative } \\
\text { Pengusaha } \\
\text { / }\end{array}$ \\
\hline & & 11 & 17.7 & 17.7
\end{tabular}

\begin{tabular}{cllll} 
Wiraswasta & & & & \\
\hline $\begin{array}{c}\text { Pegawai } \\
\text { Swasta }\end{array}$ & 21 & 33.9 & 33.9 & 51.6
\end{tabular}

\begin{tabular}{ccccc} 
Swasta & & & & p \\
\hline Pegawai & 6 & 9.7 & 9.7 & $61.3 \mathrm{p}$
\end{tabular}

\begin{tabular}{ccccr} 
Negeri & & & & 11 kon \\
\hline Pelajar/ & 24 & 38.7 & 38.7 & 100 atas Rp \\
Mahasiswa & & & & $17.7 \%$. \\
\hline Total & 62 & 100 & 100 &
\end{tabular}

Karakteristik Responden Berdasarkan Tingkat Pendapatan

\begin{tabular}{|c|c|c|c|c|}
\hline & $\begin{array}{c}\text { Freq } \\
\text { uenc } \\
\mathrm{y}\end{array}$ & $\begin{array}{c}\text { Perce } \\
\mathrm{nt}\end{array}$ & $\begin{array}{c}\text { Valid } \\
\text { Perce } \\
\text { nt }\end{array}$ & $\begin{array}{c}\text { Cumul } \\
\text { ative } \\
\text { Percen } \\
t \\
\end{array}$ \\
\hline$<2.000 .000$ & 16 & 25.8 & 25.8 & 25.8 \\
\hline $\begin{array}{c}2.000 .000- \\
4.999 .999 \\
\end{array}$ & 17 & 27.4 & 27.4 & 53.2 \\
\hline $\begin{array}{c}5.000 .000- \\
10.000 .000\end{array}$ & 18 & 29 & 29 & 82.3 \\
\hline$>10.000 .000$ & 11 & 17.7 & 17.7 & 100 \\
\hline Total & 62 & 100 & 100 & \\
\hline
\end{tabular}

Klasifikasi responden berdasarkan tingkat pendapatan dengan jumlah responden sebanyak 62 orang, dapat diperoleh hasil bahwa rata - rata konsumen yang datang ke Tea Addict yang memiliki tingkat pendapatan antara Rp 5.000.000 - Rp 10.000.000 sebanyak 18 konsumen dengan persentase Sebesar 29\%. Selain itu, ada juga konsumen Tea Addict yang memiliki pendapatan antara Rp 2.000.000 - Rp 4.999.999 sebanyak 17 orang dengan persentase sebesar $27,4 \%$. Sebanyak 16 konsumen memiliki tingkat pendapatan dibawah Rp 2.000.000 dengan persentase sebesar $25,8 \%$. Sisanya sebanyak memiliki tingkat pendapatan di Tabel 8

Klasifikasi responden berdasarkan pekerjaan dengan jumlah responden sebanyak 62 orang, dapat diperoleh hasil bahwa 38,7\% atau sebanyak 24 konsumen yang datang ke Tea Addict adalah pelajar / mahasiswa. Sementara itu, konsumen yang berprofesi sebagai pegawai swasta berjumlah 21 konsumen dengan persentase sebesar 33,9\%. Konsumen yang datang ke Tea Addict yang berprofesi sebagai pengusaha / wiraswasta
Karakteristik Responden Berdasarkan Status

\begin{tabular}{ccccc} 
& $\begin{array}{c}\text { Freque } \\
\text { ncy }\end{array}$ & $\begin{array}{c}\text { Perce } \\
\text { nt }\end{array}$ & $\begin{array}{c}\text { Valid } \\
\text { Percent }\end{array}$ & $\begin{array}{c}\text { Cumula } \\
\text { tive } \\
\text { Percent }\end{array}$ \\
\hline Menikah & 25 & 40.3 & 40.3 & 40.3 \\
\hline $\begin{array}{c}\text { Belum } \\
\text { Menikah }\end{array}$ & 37 & 59.7 & 59.7 & 100 \\
\hline Total & 62 & 100 & 100 &
\end{tabular}

Klasifikasi responden berdasarkan status dengan jumlah responden sebanyak 62 orang, dapat diperoleh hasil bahwa 59,7\% atau 
sebanyak 37 konsumen yang datang ke Tea Addict belum menikah. Sementara itu, konsumen yang sudah menikah berjumlah 25 konsumen dengan persentase sebesar $40,3 \%$.

Tabel 9

Karakteristik Responden Berdasarkan Referensi

\begin{tabular}{ccccc} 
& $\begin{array}{c}\text { Frequ } \\
\text { ency }\end{array}$ & $\begin{array}{c}\text { Perce } \\
\text { nt }\end{array}$ & $\begin{array}{c}\text { Valid } \\
\text { Perce } \\
\text { nt }\end{array}$ & $\begin{array}{c}\text { Cumulativ } \\
\text { e Percent }\end{array}$ \\
\hline Keluarga & 7 & 11.3 & 11.3 & 11.3 \\
\hline Teman & 46 & 74.2 & 74.2 & 85.5 \\
\hline $\begin{array}{c}\text { Media } \\
\text { (TV, } \\
\text { Cetak) }\end{array}$ & 6 & 9.7 & 9.7 & 95.2 \\
\hline $\begin{array}{c}\text { Lain }- \\
\text { Lain }\end{array}$ & 3 & 4.8 & 4.8 & 100 \\
\hline Total & 62 & 100 & 100 &
\end{tabular}

Klasifikasi responden yang datang ke Tea Addict berdasarkan referensi dapat dilihat dari 62 responden, sebanyak 46 konsumen yang datang ke Tea Addict berdasarkan referensi teman dengan persentase sebanyak $74,2 \%$. Selain itu konsumen yang datang berdasarkan referensi keluarga berjumlah 7 orang dengan persentase sebesar 11,3\%. Sebanyak 6 konsumen datang ke Tea Addict berdasarkan referensi dari media seperti TV, majalah, dan koran dengan persentase sebesar 9,7\%. Sisanya sebanyak 3 konsumen datang berdasarkan referensi selain tiga referensi diatas yakni berdasarkan referensi dari kampus seperti dosen dan partner bisnis dengan persentase sebesar $4,8 \%$.

\section{Tabel 10}

Karakteristik Responden Berdasarkan Frekuensi Kedatangan

\begin{tabular}{ccccc} 
& $\begin{array}{c}\text { Frequ } \\
\text { ency }\end{array}$ & $\begin{array}{c}\text { Perce } \\
\text { nt }\end{array}$ & $\begin{array}{c}\text { Valid } \\
\text { Perce } \\
\text { nt }\end{array}$ & $\begin{array}{c}\text { Cumulative } \\
\text { Percent }\end{array}$ \\
\hline 1 kali & 20 & 32.3 & 32.3 & 32.3 \\
\hline $\begin{array}{c}2-3 \\
\text { kali }\end{array}$ & 10 & 16.1 & 16.1 & 48.4 \\
\hline $\begin{array}{c}4-5 \\
\text { kali }\end{array}$ & 22 & 35.5 & 35.5 & 83.9 \\
\hline $\begin{array}{c}>5 \\
\text { kali }\end{array}$ & 10 & 16.1 & 16.1 & 100 \\
\hline Total & 62 & 100 & 100 &
\end{tabular}

Klasifikasi responden yang datang ke Tea Addict berdasarkan frekuensi kedatangan dapat dilihat dari 62 responden, sebanyak 22 konsumen yang datang ke Tea Addict sebanyak $4-5$ kali dalam jangka waktu satu bulan dengan persentase $35,5 \%$. Sementara itu, sebanyak 20 konsumen hanya pernah datang ke Tea Addict sebanyak 1 kali dengan persentase $32,3 \%$. Konsumen lain yang datang ke Tea Addict sebanyak $2-3$ kali dalam sebulan memiliki jumlah yang sama dengan konsumen yang datang ke Tea Addict lebih dari 5 kali dalam sebulan yaitu, dengan jumlah 10 konsumen dan persentase sebesar masing masing $16,1 \%$.

Berdasarkan hasil korelasi pearson didapat nilai sebagai berikut untuk pengaruh kebiasaan minum teh dengan gaya hidup konsumen di Tea Addict:

\section{Tabel 11}

Pengaruh Kebiasaan Minum Teh terhadap Gaya Hidup Konsumen di Tea Addict

\begin{tabular}{|c|c|c|c|}
\hline & & $\begin{array}{c}\text { Kebiasaar } \\
\text { Minum } \\
\text { Teh }\end{array}$ & $\begin{array}{l}\text { Gaya } \\
\text { Hidup }\end{array}$ \\
\hline \multirow{3}{*}{$\begin{array}{c}\text { Kebiasaan } \\
\text { Minum } \\
\text { Teh }\end{array}$} & $\begin{array}{c}\text { Pearson } \\
\text { Correlation }\end{array}$ & 1 & 0.123 \\
\hline & $\begin{array}{l}\text { Sig. (2- } \\
\text { tailed) }\end{array}$ & & 0.34 \\
\hline & $\mathrm{N}$ & 62 & 62 \\
\hline \multirow[t]{3}{*}{$\begin{array}{l}\text { Gaya } \\
\text { Hidup }\end{array}$} & $\begin{array}{c}\text { Pearson } \\
\text { Correlation }\end{array}$ & 0.123 & 1 \\
\hline & $\begin{array}{l}\text { Sig. (2- } \\
\text { tailed) }\end{array}$ & 0.34 & \\
\hline & $\mathrm{N}$ & 62 & 62 \\
\hline
\end{tabular}

Berdasarkan data yang di peroleh, dapat dilihat hubungan antara kebiasaan minum teh dan gaya hidup konsumen di Tea Addict sebesar 0,123 menunjukkan bahwa terdapat hubungan yang sangat lemah antara kebiasaan minum teh dan gaya hidup konsumen di Tea Addict. Hal ini menandakan bahwa responden yang meminum teh di Tea Addict bukan merupakan kebiasaan dan minum teh bagi mereka bukan sebagai bagian dari gaya hidup mereka sehari - hari.

Tabel 12

Persentase Hubungan Kebiasaan Minum Teh dengan Gaya Hidup Konsumen di Tea Addict Model Summary

\begin{tabular}{|c|c|c|c|c|}
\hline Model & $\mathrm{R}$ & $\begin{array}{c}\mathrm{R} \\
\text { Square }\end{array}$ & $\begin{array}{c}\text { Adjusted } \\
\text { R } \\
\text { Square }\end{array}$ & $\begin{array}{l}\text { Std. Error } \\
\text { of the } \\
\text { Estimate }\end{array}$ \\
\hline 1 & $123^{\mathrm{a}}$ & 0.015 & -0.001 & 0.4731 \\
\hline
\end{tabular}

a. Predictors: (Constant), KebiasaanMinumTeh

$$
\begin{gathered}
\mathbf{K d}=\mathbf{R}^{2} \times 100 \% \\
\mathbf{K d}=\mathbf{0 , 0 1 5} \times 100 \% \\
\mathbf{K d}=\mathbf{1 , 5 \%}
\end{gathered}
$$

Kemudian bila ditinjau dari penghitungan korelasi determinasi menunjukkan bahwa kebiasaan minum teh hanya mempengaruhi 
gaya hidup konsumen di Tea Addict sebesar $1,5 \%$. Sedangkan sisanya sebesar 98,5\% dipengaruhi oleh hal - hal lain yang tidak diuji dalam Proyek Akhir ini. Hal - hal lain bisa ditinjau dari segi demografi konsumen yang datang ke Tea Addict yang kebanyakan berusia 17 tahun - 25 tahun menunjukkan masa - masa tersebut masih banyak konsumen pada usia tersebut yang mengkonsumsi teh di Tea Addict hanya sekedar untuk menghabiskan waktu untuk melakukan kegiatan bisnis dan untuk sekedar berkumpul atau makan di luar.

Tabel 13

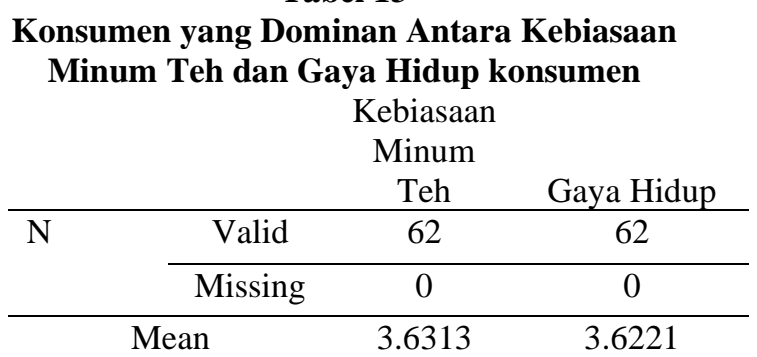

Berdasarkan Tabel diatas, dapat diketahui bahwa konsumen yang datang ke Tea Addict datang ke sana karena benar - benar seorang pecinta teh yang mengerti manfaat teh dengan nilai sebesar 3,6313 lebih besar nilainya dibandingkan dengan melakukan kegiatan meminum teh hanya sebagai gaya hidup dengan nilai sebesar 3,6221. Nilai rata - rata tanggapan responden berada pada tingkat kurang setuju mengarah ke pernyataan setuju menandakan bahwa responden belum semuanya mengetahui tentang manfaat teh dan belum semua menganggap minum teh tersebut sebagai suatu kebiasaan. Namun, bila dibandingkan dengan gaya hidup, responden condong lebih mengarah kepada alasan minum teh karena sudah terbiasa untuk meminum teh dan mengetahui sedikit tentang manfaat teh dibandingkan karena gaya hidup, sehingga dapat diambil kesimpulan bahwa minum teh belum merupakan gaya hidup pada konsumen di Tea Addict.

\section{Tabel 14}

\section{Tanggapan Responden Mengenai Peryataan: Kebiasaan Minum Teh Setiap Hari dan Merupakan dari Bagian Gaya Hidup Anda}

\begin{tabular}{llcccc} 
& & $\begin{array}{c}\text { Fal } \\
\text { encyu }\end{array}$ & $\begin{array}{c}\text { id } \\
\%\end{array}$ & $\begin{array}{c}\text { Cumulat } \\
\text { ive \% }\end{array}$ \\
\hline $\begin{array}{l}\text { Val } \\
\text { id }\end{array}$ & $\begin{array}{l}\text { Sangat } \\
\text { Tidak }\end{array}$ & 1 & 1. & 1.6 & 1.6 \\
& & 6 & & \\
& Setuju & & & & \\
\cline { 2 - 6 } & Tidak & 6 & 9. & 9.7 & 11.3 \\
& Setuju & & 7 & & \\
\cline { 2 - 6 } & Kuran & 18 & 29 & 29 & 40.3 \\
& $\begin{array}{l}\text { g } \\
\text { Setuju }\end{array}$ & & & & \\
\cline { 2 - 6 } & Setuju & 31 & 50 & 50 & 90.3 \\
\cline { 2 - 6 } & Sangat & 6 & 9. & 9.7 & 100 \\
& Setuju & & 7 & & \\
\cline { 2 - 6 } Total & 62 & 10 & 100 & \\
& & 0 & &
\end{tabular}

Berdasarkan Tabel di atas dapat diketahui bahwa konsumenTea Addict sebanyak 6 konsumen dengan persentase sebesar 9,7\% menyatakan sangat setuju dan sebanyak 31 konsumen dengan persentase sebesar 50\% menyatakan setuju bahwa kebiasaan minum teh setiap hari merupakan bagian dari gaya hidup konsumen. Sisanya, sebanyak 18 konsumen dengan persentase sebesar $29 \%$ menyatakan kurang setuju dengan pernyataan tersebut. Sementara itu, ada 6 konsumen dengan persentase sebesar $9,7 \%$ tidak setuju dan hanya 1 konsumen dengan persentase sebesar 1,6\% menyatakan sangat tidak setuju bahwa kebiasaan minum teh setiap hari bukan merupakan bagian dari gaya hidup mereka.

Setengah dari konsumen Tea Addit setuju bahwa kebiasaan minum teh setiap hari merupakan bagian dari gaya hidup mereka. Gaya hidup menurut Kotler (2002:192) adalah pola hidup seseorang di dunia yang diekspresikan dalam aktivitas, minat, dan opininya. Dalam hal ini, aktivitas dan minat yang dilakukan adalah kegiatan minum teh dan ketertarikan konsumen pada teh. Demikian juga dengan opini, setiap konsumen mengkonsumsi teh dengan tujuan yang berbeda - beda menurut pendapat konsumen tersebut. 
Tabel 15

Tanggapan Responden mengenai pernyataan : Gaya hidup sehat dapat dimulai dengan mengkonsumsi minuman teh

\begin{tabular}{|c|c|c|c|c|c|}
\hline & & $\begin{array}{c}\text { Frequen } \\
\text { cy }\end{array}$ & $\%$ & $\begin{array}{c}\text { Valid } \\
\%\end{array}$ & $\begin{array}{c}\text { Cum } \\
\text { ulativ } \\
\text { e } \%\end{array}$ \\
\hline \multirow{7}{*}{$\begin{array}{l}\mathrm{Va} \\
\mathrm{lid}\end{array}$} & Sangat & 0 & 0 & 0 & 0 \\
\hline & $\begin{array}{l}\text { Tidak } \\
\text { Setuju }\end{array}$ & & & & \\
\hline & $\begin{array}{l}\text { Tidak } \\
\text { Setuju }\end{array}$ & 5 & 8.1 & 8.1 & 8.1 \\
\hline & $\begin{array}{l}\text { Kurang } \\
\text { Setuju }\end{array}$ & 6 & 9.7 & 9.7 & 17.7 \\
\hline & Setuju & 35 & 56.5 & 56.5 & 74.2 \\
\hline & $\begin{array}{l}\text { Sangat } \\
\text { Setuju }\end{array}$ & 16 & 25.8 & 25.8 & 100 \\
\hline & Total & 62 & 100 & 100 & \\
\hline
\end{tabular}

Berdasarkan di atas dapat diketahui bahwa konsumen Tea Addict sebanyak 16 konsumen dengan persentase sebesar 25,8\% menyatakan sangat setuju dan 35 konsumen dengan persentase sebesar $56,5 \%$ menyatakan setuju bahwa gaya hidup sehat dapat dimulai dengan mengkonsumsi minuman teh. Sisanya, sebanyak 6 konsumen dengan persentase sebesar 9,7\% menyatakan kurang setuju dengan pernyataan tersebut. Sementara itu, hanya 5 konsumen dengan persentase $8,1 \%$ yang menyatakan tidak setuju bahwa gaya hidup sehat bukan hanya dapat dilakukan dengan mengkonsumsi teh, tetapi bisa juga dengan hal - hal lain seperti mengkonsumsi buah dan sayuran misalnya.

\section{Hasil Hipotesis}

Berdasarkan hasil dan pembahasan mengenai hubungan antara kebiasaan minum teh terhadap gaya hidup konsumen di Tea Addict, Jakarta, maka kita bisa mengetahui bahwa hipotesis yang telah dirinci dapat diketahui hipotesis mana yang berlaku untuk penelitian ini.

Dari kesimpulan semua yakni, tidak terdapat korelasi antara kebiasaan minum teh dan gaya hidup konsumen di Tea Addict, Jakarta.

\section{SIMPULAN DAN SARAN}

\section{A. SIMPULAN}

Berdasarkan hasil pengolahan data dan analisa mengenai "Pengaruh Kebiasaan Minum Teh Berkualitas Terhadap Gaya Hidup Konsumen Di Tea Addict, Jakarta" maka dapat ditarik kesimpulan yang berhubungan dengan tujuan penelitian yang telah ditetapkan. Adapun kesimpulan - kesimpulan tersebut sebagai berikut :

a. Dari hasil dan pembahasan mengenai hubungan antara kebiasaan minum teh dan gaya hidup konsumen di Tea Addict dapat dilihat bahwa hubungan antara kedua variabel tersebut sebesar 0,123 . Dimana angka tersebut menunjukkan bahwa terdapat hubungan yang sangat lemah antara kebiasaan minum teh dan gaya hidup konsumen di Tea Addict. Sementara itu, kebiasaan minum teh mempengaruhi gaya hidup konsumen sebesar $1,5 \%$, sisanya sebesar $98,5 \%$ dipengaruhi oleh hal - hal lain yang tidak diuji dalam karya tulis ini.

Dengan kata lain kebiasaan minum teh tidak memiliki pengaruh terhadap gaya hidup konsumen di Tea Addict, Jakarta.

Dimana kita dapat melihat pada tabel 14 dan tabel 15, dimana responden dalam hal menjawab pertanyaan yang diajukan didalam penelitian ini, perihal kebiasaan minum teh dalam kesehariannya dan memulainya minum teh adalah awal dari gaya hidup, sebagian besar responden masih menjawab setuju berbanding dari hasil penelitian diatas dimana sebagian besar hasil menunjukan bahwa minum teh tidak mempengaruhi gaya hidup. Disini sekali lagi menunjukan bahwa, kebiasaan minum teh TIDAK mempunyai pengaruh yang besar terhadap gaya hidup di masyarakat.

b. Sedangkan berdasarkan karakteristik responden, dapat disimpulkan bahwa konsumen yang datang ke Tea Addict rata - rata berusia antara $17-25$ tahun dengan persentase sebesar $43,5 \%$. Kebanyakan konsumen tersebut adalah perempuan dengan jumlah persentase sebesar 53,2\%. Perempuan cenderung lebih konsumtif dan selalu ingin bersosialiasa dibandingkan dengan pria. 


\section{B. SARAN}

Setelah hasil didapat, maka dapat diberikan masukan atau saran-saran yang mungkin dapat menjadi masukan untuk peningkatan operasional di Tea Addict.

a. Berdasarkan kesimpulan mengenai bahwa tidak terdapat pengaruh antara kebiasaan minum teh dengan gaya hidup konsumen di Tea Addict, dapat diambil saran bahwa ada baiknya dilakukan penelitian lebih lanjut mengenai konsumen di Tea Addict yang difokuskan pada faktor demografi yang lebih mendalam.

b. Berdasarkan pekerjaan, pelajar/mahasiswa merupakan konsumen yang paling banyak datang ke Tea Addict, dimana pelajar/mahasiswa belum memiliki penghasilan tetap dan belum memiliki kebutuhan yang konsisten.

\section{DAFTAR PUSTAKA}

Ara, Rossi.2010. 1001 Teh - Dari Asal Usul, Tradisi, Khasiat Hingga Racikan Teh. Edisi I. Yogyakarta : Penerbit Andi.

Davis, Bernard et al. 2008. Food and Beverage Management. Fourth Edition. Slovenia : Elsevier

Dewi, Dian Paramita. 2010. Analisis Tipe Perilaku Konsumen Dalam Membeli Teh Di Pasar TradisionalKabupaten Wonogiri. Skripsi S1 Fakultas PertanianUniversitas Sebelas Maret.Surakarta.

Engel, James F., Blackwell, Roger D. \& Miniard, Paul W. 1995. Perilaku Konsumen. (Alih Bahasa: F. X. Budiyanto) Jilid I. Jakarta : Binarupa Aksara.

1996. Perilaku Konsumen. (Alih Bahasa: F. X. Budiyanto). Jilid II. Jakarta : Binarupa Aksara.

Indarto, Prawoto. 2007. Teh Minuman Bangsa

- Bangsa di Dunia. Cetakan 1. Jakarta : Pawon Publishing.

Kusmayadi, dan Endar Sugiarto. 2000. Metodologi Penelitian dalam Bidang Kepariwisataan, Jakarta: PT. Gramedia Pustaka Umum.
Nazaruddin, dan F.B. Paimin. 1993. Pembudidayaan dan Pengolahan Teh. Jakarta: Penebar Swadaya.

Nugraheni,P.N.A.2003.Perbedaan Kecenderungan Gaya Hidup Hedonis Pada Remaja Ditinjau dari Lokasi Tempat Tinggal. Skripsi (tidak diterbitkan).

Solomon, Michael R. 2011. Consumer Behavior : Buying, Having, and Being. Ninth Edition. New Jersey : Pearson Education, Inc.

Sumarwan, Ujang. 2003. Perilaku Konsumen "Teori dan Penerapannya dalam Pemasaran. Jakarta : Ghalia Indonesia.

Syahriyanti, Eti. 2009. I Love Coffee and Tea - Ngopi dan Ngeteh sebagai Bagian dari Gaya Hidup. Cetakan 1. Yogyakarta : DIVA Press.

Wells, WD dan Tigertt DJ. 1971. Activities, interests, and Opinions. Journal of Advertising Research, 11 August, 27 -35 .

Wiwoho, Ardjuno. 2008. Pengetahuan Tata Hidang. Jakarta : Esensi, divisi Penerbit Erlangga.

Situs :

http://www.artikata.com/arti-183555teahouse.html

http://asliblogspot.blogspot.com/2012/05/men dapatkan-dan-menikmaticitarasateh.html oleh Iskaruji.

http://www.bbc.co.uk/2/hi/5281046.stm\&clie $\mathrm{nt}=\mathrm{msrim} \& \mathrm{q}=\mathrm{dr}+$ carrie + ruxton $\& \mathrm{sa}=$ $\underline{X \& \text { ei }=x K g 3 \text { ULedOaqBygHUoIC4A }}$ g\&ved $=0 \mathrm{CCsQFjAE}$

http://www.fmltea.com/Teainfo/teachemistry\%20.htm

http://jualteh.com/seni-menyeduh-teh-yangbaik-dan-benar/ oleh Irawan,

http://jurnalsdm.blogspot.com/2009/07/produkdefinisi-klasifikasi-dimensi_30.html

http://www.kalbe.co.id/files/cdk/files/144_16 AntioxidantTea.pdf/144_16Antioxida ntTea.tml oleh Sulistyowati Tuminah.

http://www.membuatblog.web.id/2010/04/pe ngertian-gaya-hidup.html 